\title{
Obituary
}

\section{Dhirendra Nath Nandi, FRCP (Edin.) FRCPsych}

Formerly Psychologist, Psychoanalyst and Psychiatrist

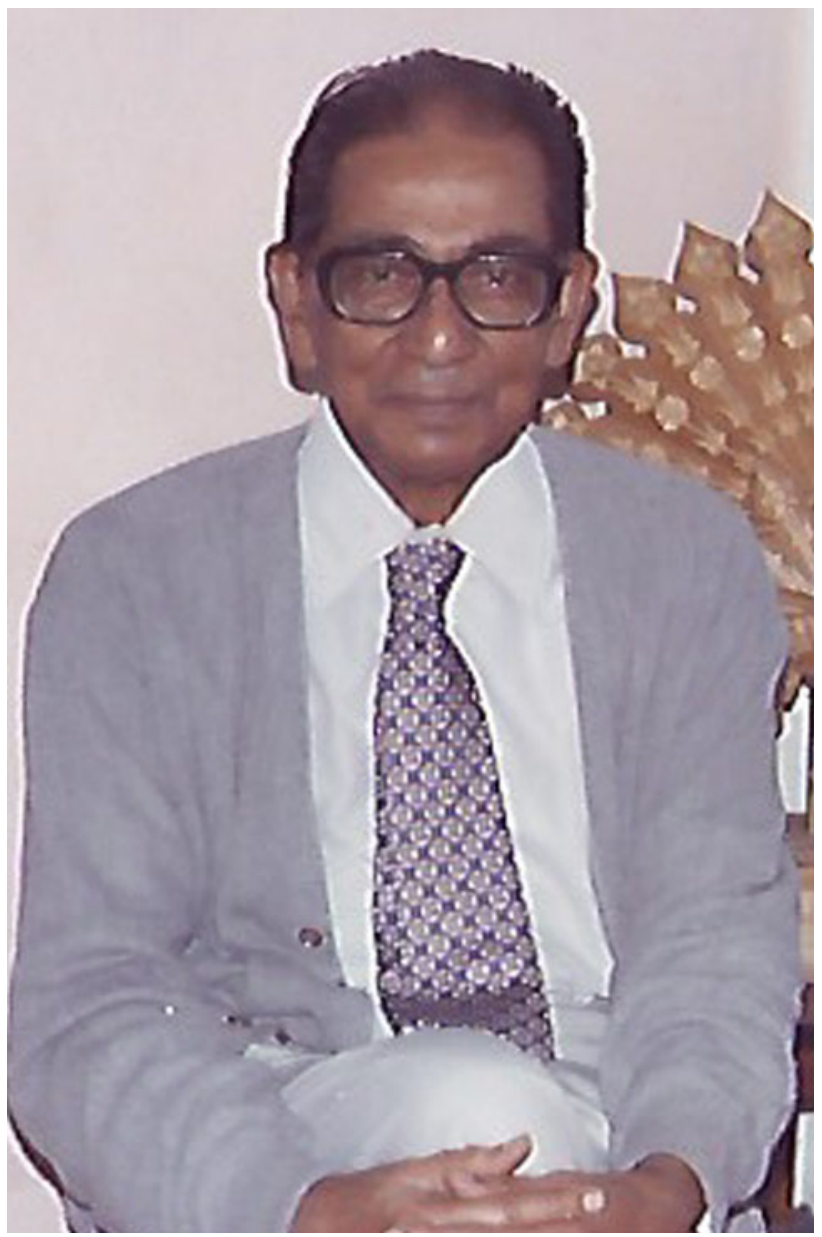

Dhirendra Nath Nandi, who passed away quietly aged 98 on 26 March 2017, was Head of the Department of Psychological Medicine at the University of Kolkata and a prominent leader of Indian psychiatry. Assisted by a team of several postgraduate students, he carried out significant epidemiological research in different tribal groups in villages of West Bengal. His research findings, which included important longitudinal data, were published not in just Indian but several British and US journals. One important finding related to a dramatic fall in hysterical and anxiety disorders with an equal rise in affective illnesses. His papers were used as standard texts in several educational programmes.

Professor Nandi had a strong interest in raising public awareness of mental health problems. He organised several public awareness programmes on his own and with the Indian Red Cross Society in different parts of Kolkata and other districts of West Bengal. He was frequently invited to be a speaker on various television shows and radio programmes to talk about mental health. In 1990 he wrote a book in Bengali on psychiatry, MonerBikar o Pratikar, which was very popular with the general public, and postgraduate students in psychology and psychiatry. In the later years of his life, he founded the Girindra Sekhar Institute of Psychological Education and Research, where he started a counselling course affiliated with a recognised university of West Bengal for graduates in basic and social sciences. He also established a popular quarterly journal in Bengali, Moner Katha, as well as running an out-patient clinic for the poor and underprivileged mentally ill, which retains its reputation to this day.

Born on 13 August 1918, in a remote village of a district of West Bengal to a poor family and losing his mother in his early childhood, Dr Nandi showed early promise in his studies. He struggled considerably in early life but showed indomitable energy in the pursuit of knowledge in medicine and psychology. After graduation from Carmichael Medical School, then the R. G. Kar Medical College and Hospital, Kolkata, in 1945, he obtained an MSc in psychology in 1950, and a PhD in psychology in 1958 from the University of Calcutta. He trained in clinical psychiatry and psychoanalysis with Professor Girindra Sekhar Bose, the eminent psychiatrist and founder of psychoanalysis and psychiatry in India, and with Professor N. N. Dey, his own maternal uncle and first editor of the Indian Journal of Psychiatry. He began his career in 1948 as a teacher, examiner and researcher in physiology at NRS Medical College and Hospital, Kolkata, where he worked for nearly 10 years.

Marrying in 1949 into a business family, he went abroad in 1960, leaving his wife and three children in Kolkata with his in-laws. He obtained his Scottish Diploma in Psychological Medicine in 1961 and became a Member of Royal College of Physicians (Edinburgh) with a special paper in psychiatry in 1963. In those days, there was no postgraduate training in psychiatry available in India. Returning to Kolkata he was appointed Associate Professor of Psychiatry at R. G. Kar Medical College and Hospital, Kolkata. In 1970 he became Head of the Department of Psychological Medicine at the University of Calcutta. He retired in 1979 as Professor of Psychiatry from R. G. Kar Medical College and Hospital, Kolkata. During his professional life he held a number of important positions in Indian psychiatry, including being President of the Indian Psycho-analytical Society for more than 20 years, and President of the Indian Psychiatric Society and Indian Association of Social Psychiatry. His contributions to the advancement of the fields of psychiatry and psychoanalysis were recognised by numerous awards and prizes.

Professor Nandi had an active interest in cooking, fishing and hunting, and travelled widely with his family and friends. It is noteworthy that his two sons are consultant psychiatrists, his daughter and younger daughter in-law are 
psychoanalysts, one grandson is undertaking a post-graduate degree in psychiatry, a second grandson is a graduate in medicine, and a third is a final-year medical student.

\section{Reference}

1 Nandi D, Banerjee G, Mukherjee S, Nandi P, Nandi S. Psychiatric morbidity of a rural Indian community: changes over a 20-year interval. $\mathrm{Br} J$ Psychiatry 2000; 176(4): 351-6.

Parthasarathi Nandi

doi:10.1192/bjb.2018.58
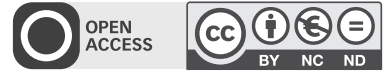

(c) The Author 2018. This is an Open Access article, distributed under the terms of the Creative Commons Attribution-NonCommercial-NoDerivatives licence (http://creativecommons.org/licenses/by-nc-nd/4.0/), which permits noncommercial re-use, distribution, and reproduction in any medium, provided the original work is unaltered and is properly cited. The written permission of Cambridge University Press must be obtained for commercial re-use or in order to create a derivative work.

\section{Donald Eccleston, FRCPsych, PhD, DSc}

\section{Formerly Professor of Psychiatry, Newcastle upon Tyne Medical School, UK}

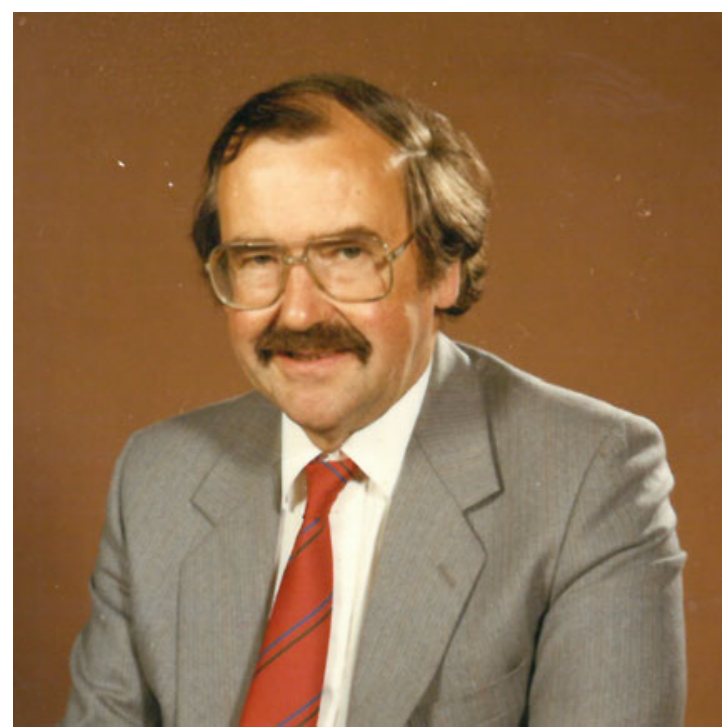

Donald (Don) Eccleston, who died recently at the age of 86 years, was one of the first to elaborate a hypothesis of depression which argued for the role of monoamines, particularly 5-hydroxytryptamine (5-HT), in the regulation of mood. He went on to translate his experimental observations into treatment for patients with refractory depressive disorders, devising the 'Newcastle cocktail' (phenelzine,
L-tryptophan and lithium). This was a pharmacological strategy offering a window of opportunity through which cognitive-behavioural therapy (CBT) and intensive nursing care could be directed to reduce the secondary handicaps of chronic depression.

In 1962, he took up a post at the Medical Research Council (MRC) Brain Metabolism Unit at the University of Edinburgh, joining a highly innovative group of psycho-pharmacologists including George Ashcroft. Between them, over the next decade, they elaborated the role of amines, in particular 5-HT, in the regulation of mood. In the absence of today's sophisticated imaging and analytical techniques, these must have been difficult experiments to conduct; his first published paper describes measuring changes in 5-HT metabolites in volunteers who were being investigated for neurological disorders by air encephalography, a procedure in which most of the cerebrospinal fluid was drained from around the brain by means of a lumbar puncture and replaced with air.

In 1966, he spent an enjoyable year at the National Institutes of Health in Bethesda, Maryland, USA, where he worked with Julius Axelrod - one of the three winners who shared the 1970 Nobel Prize in Physiology or Medicine for their discovery of the actions of neurotransmitters in regulating the metabolism of the nervous system. He then returned to Edinburgh to be appointed Deputy Director of the MRC unit, where he continued to elaborate the monoamine hypothesis of depression by demonstrating that drugs which influence mood in humans may alter the turnover of $5-\mathrm{HT}$, and levels of $5-\mathrm{HT}$, in the brains of animals.

On appointment to the Chair of Psychiatry in Newcastle upon Tyne in 1977, he set up his own research unit at 1-4 Claremont Terrace and established the Regional Affective Disorders Unit, the longest-standing in-patient unit for the treatment of depression in the UK. The Newcastle Chronic Depression Study, published in 1987, described new therapeutic approaches to treatment-resistant chronic depression, including the use of CBT, which was just emerging from US research as having antidepressant potential. The Chronic Depression Study demonstrated a now well-accepted principle in the treatment of chronic depression, namely that intensive drug treatment may be a necessary preliminary that enables effective rehabilitation of the secondary handicaps. Donald promoted development of psychotherapeutic treatments, particularly CBT, and innovative nursing practices for his patients, and became increasingly interested in predictors of refractory depression and its prophylaxis.

While he was Head of the Academic Department of Psychiatry in Newcastle, lecturer and fellowship posts in his department were always in demand; it was a happy place to work, with many appointees going on to professorial appointments in psychiatry, psychology, nursing and neuroscience, both within and beyond Newcastle. He also trained a generation of research-supportive National Health Service (NHS) clinicians who, through him, had been exposed to evidencebased medicine just as the term began to be coined. Early on, he realised the limitations of an academic ivory tower. As the management of the NHS started to change, he recognised the mutual benefits of close partnerships between academia and care providers. 